\title{
EDITORIAL
}

\section{Rationale and methods of the European Food Consumption Validation (EFCOVAL) Project}

\author{
EJ de Boer ${ }^{1}$, N Slimani ${ }^{2}$, P van 't Veer ${ }^{3}, \mathrm{H}_{\text {Boeing }}^{4}$, M Feinberg ${ }^{5}$, C Leclercq $^{6}$, E Trolle ${ }^{7}$, \\ P Amiano ${ }^{8}$, LF Andersen ${ }^{9}$, H Freisling ${ }^{2}$, A Geelen ${ }^{3}$, U Harttig ${ }^{4}$, I Huybrechts ${ }^{10}$, A Kaic-Rak ${ }^{11}$, \\ L Lafay $^{12}$, IT Lillegaard ${ }^{9}, \mathrm{~J} \mathrm{Ruprich}^{13}$, JH de Vries ${ }^{3}$ and MC Ocké ${ }^{1}$, on behalf of the \\ EFCOVAL Consortium
}

\begin{abstract}
${ }^{1}$ National Institute for Public Health and the Environment (RIVM), Bilthoven, The Netherlands; ${ }^{2}$ Dietary Exposure Assessment Group, International Agency for Research on Cancer, Lyon, France; ${ }^{3}$ Division of Human Nutrition, Wageningen University, Wageningen, The Netherlands; ${ }^{4}$ Department of Epidemiology, German Institute of Human Nutrition, Potsdam-Rehbruecke (DIfE), Nuthetal, Germany; Institut National de la Recherche Agronomique, Paris, France; ${ }^{6}$ National Research Institute for Food and Nutrition (INRAN), Rome, Italy; ${ }^{7}$ Division of Nutrition, National Food Institute, Technical University of Denmark, Soeberg, Denmark; ${ }^{8}$ Public Health Division of Gipuzkoa, San Sebastian and Epidemiologia y Salud Pública (CIBERESP), Barcelona, Spain; ${ }^{9}$ Department of Nutrition, Institute of Basic Medical Sciences, University of Oslo, Oslo, Norway; ${ }^{10}$ Department of Public Health, Faculty of Medicine and Health Sciences, Ghent University, Ghent, Belgium; ${ }^{11}$ Akademija Medicinskih Znanostl Hrvatske, Zagreb, Croatia; ${ }^{12}$ Food intake and Nutritional Epidemiology Unit, French agency for food, environmental and occupational health safety (ANSES), Maisons-Alfort, France and ${ }^{13}$ National Institute of Public Health, Brno, Czech Republic
\end{abstract}

Background/Objectives: The overall objective of the European Food Consumption Validation (EFCOVAL) Project was to further develop and validate a trans-European food consumption method to be used for the evaluation of the intake of foods, nutrients and potentially hazardous chemicals within the European population.

Subjects/Methods: The EFCOVAL Project was carried out by 13 institutes from 11 European countries. The main activities were centered on the three main objectives of the project organized in different sub-projects.

Results: In EFCOVAL, EPIC-Soft (the software developed to conduct 24-h dietary recalls (24-HDRs) in the European Prospective Investigation into Cancer and Nutrition (EPIC) Study) was reprogrammed and adapted according to prioritized specifications, resulting in a software program working under the Windows operating system. In parallel of the EPIC-Soft development, the repeated 24-HDR method using EPIC-Soft and a food propensity questionnaire was evaluated against biomarkers in 24-h urine collections and in blood samples among adults from Belgium, the Czech Republic, (the South of) France, the Netherlands and Norway. As a result from an expert workshop on a proposed dietary assessment method for children (4-12 years), the suggested method was tested in a feasibility study in Denmark and Spain among children of 4-5, 7-8 and 12-13 years. To ensure that collected data had sufficient detail in food description for the assessment of additives and contaminants to foods the EPIC-Soft databases were adapted. Finally, the EFCOVAL Consortium developed a statistical tool (Multiple Source Method) for estimating the usual intake and distribution, which has been tested using real food consumption data and compared with three other statistical methods through a simulation study. In addition, a methodology was developed to quantify uncertainty due to portion-size estimation in usual intake distributions.

Conclusion: The findings of EFCOVAL provide sufficient evidence to conclude that the repeated 24-HDR using EPIC-Soft for standardization in combination with a food propensity questionnaire and modeling of usual intake is a suitable method for panEuropean surveillance of nutritional adequacy and food safety among healthy adults and maybe in children aged 7 years and older.

European Journal of Clinical Nutrition (2011) 65, S1-S4; doi:10.1038/ejcn.2011.82

Keywords: EFCOVAL; food consumption survey; 24-h dietary recall; Europe; EPIC-Soft; validation

Correspondence: Dr EJ de Boer, National Institute for Public Health and the Environment (RIVM), PO Box 1, 3720 BA Bilthoven, The Netherlands.

E-mail: evelien.de.boer@rivm.nl 


\section{Introduction}

Dietary monitoring data are essential to develop and evaluate policy measures for a healthier and safer diet. In Europe, most countries conduct national food consumption surveys. The methods and design of the existing surveys differ however across countries. In surveys on adults, many countries apply 24-h dietary recalls (HDRs), but food records are also widely used, whereas for children the food record is more often preferred methodology (EFSA, 2009; Elmadfa et al., 2009). As a consequence, dietary intake data from the various national food consumption surveys in Europe have limited comparability and cannot be pooled.

As many food safety and nutritional issues need to be addressed at the European Union level, standardization of dietary monitoring data across its member states is, therefore, of a major importance (EFSA, 2008; Trubswasser and Branca, 2009). This need for comparable European food consumption data was the rationale for a call for proposals in the EU Sixth Framework Program 'Developing a trans-European methodology to study food consumption' (FP6-2004-FOOD-3-BT5.4.2.2). The European Food Consumption Validation (EFCOVAL) Project addressed the objectives of this call.

The EFCOVAL Project could build upon previous projects, most notably the 'European Food Consumption Survey Method' (EFCOSUM) Project. In the EFCOSUM Project, recommendations for reliable and comparable trans-national collection of dietary data were formulated (Brussaard et al., 2002). The overall objective of EFCOVAL was to further develop and validate a trans-European food consumption method to be used for the evaluation of the intake of foods, nutrients and potentially hazardous chemicals within the European population. Starting point of EFCOVAL was the recommended method by EFCOSUM, that is, the collection of 24-HDRs to obtain reliable and comparable data from European countries using the computer-assisted interview program EPIC-Soft (the software developed to conduct 24-HDRs in the European Prospective Investigation into Cancer and Nutrition (EPIC) Study). The most important activities of EFCOVAL focused on three main objectives, that is, (1) to upgrade and adapt EPIC-Soft, and validate two nonconsecutive 24-HDRs using EPIC-Soft in adults; (2) to define and investigate the applicability of the most appropriate dietary assessment method for younger age groups and expand the applicability of EPIC-Soft for use in exposure assessment of some potentially hazardous chemicals and (3) to improve the methodology and statistical methods that estimate usual intake distributions from short-term dietary intake information and develop a methodology to quantify uncertainty in usual intake distributions.

\section{Materials and methods}

The EFCOVAL Project was carried out by researchers from 11 European countries. Activities of the project included software development, validation and feasibility studies, literature research and plenary sessions. In addition, several specific workshops with invited external experts were organized in order to discuss and decide on proposed strategies and methods. All participating institutes contributed to one or more specific objectives. The results of the activities contributed to papers, which are published in this supplement or elsewhere. The main activities were centered on the three main objectives of the project organized in different work packages and their specific tasks.

\section{Results}

Objective 1: the upgrade and adaptation of EPIC-Soft and the validation of two non-consecutive 24-HDRs using EPIC-Soft

Upgrade and adaptation of EPIC-Soft. EPIC-Soft was originally developed in the early nineties in the frame of the EPIC calibration Study (Slimani et al., 1999, 2000). In the EFCOSUM Project, it was concluded that EPIC-Soft has several advantages for use in pan-European monitoring surveys. However, EPIC-Soft was not yet suitable for all requirements of European dietary monitoring and needed to be updated to be used in a modern Windows environment (Slimani and Valsta, 2002).

In EFCOVAL, the further development of EPIC-Soft started with an inventory of problems and shortcomings experienced in applying the EPIC-Software in (national) dietary monitoring surveys. Therefore, an EPIC-Soft specifications questionnaire was completed by the coordinating institutes that used EPIC-Soft in their national food consumption survey (Belgium, Germany, the Netherlands and Spain) and previous users of EPIC-Soft outside this network. Subsequently, a proposal with prioritized specifications was discussed during a workshop conducted with representatives from the EFCOVAL Consortium and external experts in the field.

The software was then reprogrammed and adapted according to the prioritized specifications, resulting in a software program working under the Windows operating system. Furthermore, one of the aims of this work package was to develop the concepts of a platform for maintenance and dissemination of EPIC-Soft (EPIC-Soft Methodology Platform) (Slimani et al., 2011).

Validity of the instrument. In parallel, the repeated 24-HDR method using EPIC-Soft was validated among adults from Belgium, Czech Republic, (the South of) France, the Netherlands and Norway. These five countries ensured a representation of different geographical areas in Europe with diverse food patterns, different levels of experience with EPIC-Soft, experience in performing dietary surveys and the availability of a food composition table. From every country included in the validation study, men $(n=60)$ and women $(n=60)$ in the range of 45-65 years of age were included in the study via convenience sampling. The research protocol was approved 
by the local ethics committees of each institute involved in the data collection, and all respondents provided signed informed consent. In the study, food and nutrient intake estimates collected with two non-consecutive 24-HDRs using EPIC-Soft, and a food propensity questionnaire were evaluated, against biomarkers in 24-h urine collections and in blood samples. The two 24-HDRs were collected using two modes of administration: one by phone and one face-to-face. A randomization schedule was created to consider a random order of the two modes of administration as well as the inclusion of all days of the week equally distributed among the subjects (Crispim et al., 2011) The critical feedbacks of the respondents involved in the EFCOVAL Study (Huybrechts et al., 2011b) and experiences of EPIC-Soft use in other studies were also evaluated (Huybrechts et al., 2011a).

At the end of the EFCOVAL Project, a workshop was organized (1) to discuss potentials and limitations of using EPIC-Soft as dietary assessment instrument in the context of pan-European dietary monitoring; (2) to inform and discuss the requirements to use EPIC-Soft; and (3) to list and discuss possibilities and barriers for harmonization of national food consumption surveys or for implementation of a panEuropean food consumption Survey (Ocke et al., 2011).

Objective 2: to define and investigate the applicability of the most appropriate dietary assessment method for younger age groups and expanding the applicability of EPIC-Soft for use in exposure assessment of potentially hazardous chemicals

Applicability of the instrument in children. EFCOSUM recognized that the applicability of EPIC-Soft to children below the age of 15 years needed to be tested (Biro et al., 2002; Brussaard et al., 2002).

In EFCOVAL, the work on younger age groups started with an expert workshop to identify the most appropriate method(s) for dietary assessment in children (4-15 years) and focused on 24-HDRs and food records (Andersen et al., 2011). As a result from the workshop, the suggested method for school children was tested in a feasibility study in Denmark and Spain among children of 4-5, 7-8 and 12-13 years (Trolle et al., 2011a, c). Finally, the developed method was evaluated against a 7-day-record, among children aged 7-14 years, collected in Denmark (Trolle et al., 2011b).

Applicability in exposure assessment. EFCOSUM recognized that EPIC-Soft needed to be adjusted to achieve information on food safety of populations (Slimani and Valsta, 2002). One of the activities with regard to dietary exposure assessment was to provide an overview of the existing European food consumption databases in relation to their current and potential use for the assessment of dietary exposure to additives, flavorings and residues of food contact materials (Le Donne et al., 2011). A second main objective focused on the adaptation of EPIC-Soft databases to ensure that collected data have sufficient detail in food description for the assessment of additives and contaminants to foods. One target category of food chemicals or families was selected as practical example all over the process of EPIC-Soft adaptations. In an explorative study, different methods of assessing dietary exposure to flavoring substances (that is, raspberry ketone, glycyrrhizinic acid, coumarin and caffeine) were compared in a stepwise approach, and the effect of the adaptation of the EPIC-Soft databases for the estimation of the dietary exposure to raspberry ketone was evaluated (Crispim et al., 2010).

Objective 3: to improve the methodology and statistical methods that estimate usual intake distributions from short-term dietary intake information and develop a methodology to quantify uncertainty in usual intake distributions

For assessing the prevalence of nutrient inadequacy and of intakes of substances that exceed thresholds of chronic toxicity, it is important to have information on usual dietary intake. A 24-HDR method provides information on shortterm intake; however repeated 24-HDRs, complement with a food propensity questionnaire designed to distinguish the usual vs occasional non-consumers, can be used to translate short-term intake information into usual intake. The EFCOSUM group compared the use of six different statistical approaches to handle the data collected by multiple 24-HDRs (Hoffmann et al., 2002). As a follow-up to this, the EFCOVAL Consortium developed a statistical tool (the Multiple Source Method) for estimating the usual intake and tested it with food consumption data (Haubrock et al., 2011).

The freely available Multiple Source Method (Harttig et al., 2011) was compared with three other statistical methods to estimate the usual intake distributions through a simulation study (Souverein et al., 2011b).

Despite standardization of methods and other efforts to reduce the reporting errors in the assessment of dietary intake, the estimates of the population mean and distributions may be affected by uncertainties. Uncertainties may relate to, for example, food coding, portion-size estimations, nutrient content and food composition tables. In EFCOVAL, uncertainties related to food intake were studied, based on a literature review. In addition, a methodology was developed to quantify uncertainty due to portion-size estimation in usual intake distributions (Souverein et al., 2011a).

\section{Conclusions}

The findings of EFCOVAL provide sufficient evidence to conclude that the repeated 24-HDR using EPIC-Soft for standardization in combination with a food propensity questionnaire and modeling of usual intake is a suitable method for pan-European surveillance of nutritional adequacy and food safety among healthy adults and maybe in 
children aged 7 years and older. The suitability of the recommended method and the use of EPIC-Soft are discussed in detail in this supplement. Furthermore, recommendations for the implementation of the method to be used for a panEuropean survey are provided.

\section{Conflict of interest}

JR received consulting fees from the Czech Technology Platform for food and healthy lifestyle. The remaining authors declare no conflict of interest.

\section{Acknowledgements}

The content of this article reflects only our views and the Community is not liable for any use that may be made of the information contained therein. The Community funding under the Sixth Framework Program for the EFCOVAL Project is acknowledged (FOOD-CT-2006-022895).

\section{References}

Andersen LF, Lioret S, Brants H, Kaic-Rak A, de Boer EJ, Amiano P et al. (2011). Recommendations for a trans-European dietary assessment method in children between 4 and 14 years. Eur J Clin Nutr 65 (Suppl 1), S58-S64.

Biro G, Hulshof KF, Ovesen L, Amorim Cruz JA (2002). Selection of methodology to assess food intake. Eur J Clin Nutr 56 (Suppl 2), S25-S32.

Brussaard JH, Lowik MR, Steingrimsdottir L, Moller A, Kearney J, De Henauw S et al. (2002). A European food consumption survey method-conclusions and recommendations. Eur J Clin Nutr 56 (Suppl 2), S89-S94.

Crispim SP, de Vries JH, Geelen A, Souverein OW, Hulshof PJ, Lafay L et al. (2011). Two non-consecutive $24 \mathrm{~h}$ recalls using EPIC-Soft software are sufficiently valid for comparing protein and potassium intake between five European centers-results from the European Food Consumption Validation (EFCOVAL) study. Br J Nutr 105, 447-458.

Crispim SP, Geelen A, Le Donne C, de Vries JH, Sette S, Raffo A et al. (2010). Dietary exposure to flavouring substances: from screening methods to detailed assessments using food consumption data collected with EPIC-Soft software. Food Addit Contam Part A Chem Anal Control Expo Risk Assess 27, 433-446.

EFSA (2008). Scientific Colloquium Summary Report-European Food Consumption Database: Current And Medium To Long-Term Strategies. EFSA: Parma.

EFSA (2009). General principles for the collection of national food consumption data in the view of a pan-European dietary survey. EFSA $J$ 7, 1-51.

Elmadfa I, Meyer A, Nowak V, Hasenegger V, Putz P, Verstraeten R et al. (2009). European Nutrition and Health Report 2009. Ann Nutr Metab 55 (Suppl 2), 1-40.

Harttig U, Haubrock J, Knüppel S, Boeing H, on behalf of the EFCOVAL Consortium (2011). The MSM program: the web-based statistics package for estimating usual dietary intake using the Multiple Source Method. Eur J Clin Nutr 65 (Suppl 1), S87-S91.

Haubrock J, Nothlings U, Volatier JL, Dekkers A, Ocke MC, Harttig U et al. (2011). Estimating usual food intake distributions by using the Multiple Source Method (MSM). J Nutr 141, 914-920.

Hoffmann K, Boeing H, Dufour A, Volatier JL, Telman J, Virtanen M et al. (2002). Estimating the distribution of usual dietary intake by short-term measurements. Eur J Clin Nutr 56 (Suppl 2), S53-S62.

Huybrechts I, Casagrande C, Nicolas G, Geelen A, Crispim SP, De Keyzer W et al. (2011a). Inventory of experiences from national/regional monitoring surveys using EPIC-Soft. Eur J Clin Nutr 65 (Suppl 1), S16-S28.

Huybrechts I, Geelen A, de Vries JH, Casagrande C, Nicolas G, De Keyzer W et al. (2011b). Respondents' evaluation of the 24-h dietary recall method (EPIC-Soft) in the EFCOVAL Project. Eur J Clin Nutr 65 (Suppl 1), S29-S37.

Le Donne C, Piccinelli R, Sette S, Leclercq C (2011). Overview of existing European food consumption databases: critical aspects in relation to their use for the assessment of dietary exposure to additives, flavourings and residues of food contact materials. Int J Food Sci Nutr 62, 121-132.

Ocké MC, Slimani N, Brants H, Buurma-Rethans E, Casagrande C, Nicolas G et al. (2011). Potential and requirements for a standardized pan-European food consumption survey using the EPIC-Soft software. Eur J Clin Nutr 65 (Suppl 1), S48-S57.

Slimani N, Casagrande C, Nicolas G, Freisling H, Huybrechts I, Ocké MC et al. (2011). The standardized computerized 24-h dietary recall method EPIC-Soft adapted for pan-European dietary monitoring. Eur J Clin Nutr 65 (Suppl 1), S5-S15.

Slimani N, Deharveng G, Charrondiere RU, van Kappel AL, Ocke MC, Welch A et al. (1999). Structure of the standardized computerized 24-h diet recall interview used as reference method in the 22 centers participating in the EPIC project. European Prospective Investigation into Cancer and Nutrition. Comput Methods Programs Biomed 58, 251-266.

Slimani N, Ferrari P, Ocke MC, Welch A, Boeing H, Liere M et al. (2000). Standardization of the 24-h diet recall calibration method used in the european prospective investigation into cancer and nutrition (EPIC): general concepts and preliminary results. Eur J Clin Nutr 54, 900-917.

Slimani N, Valsta L (2002). Perspectives of using the EPIC-SOFT programme in the context of pan-European nutritional monitoring surveys: methodological and practical implications. Eur J Clin Nutr 56 (Suppl 2), S63-S74.

Souverein OW, De Boer WJ, Geelen A, Van der Voet H, de Vries JH, Feinberg M et al. (2011a). Uncertainty in intake due to portion size estimation in 24-h recalls varies between food groups. I Nutr (accepted for publication).

Souverein OW, Dekkers AL, Geelen A, Haubrock J, de Vries JH, Ocké MC et al. (2011b). Comparing four methods to estimate usual intake distributions. Eur J Clin Nutr 65 (Suppl 1), S92-S101.

Trolle E, Amiano P, Ege M, Bower E, Lioret S, Brants H et al. (2011a). Feasibility of repeated 24-h dietary recalls combined with a foodrecording booklet, using EPIC-Soft, among preschoolers. Eur J Clin Nutr 65 (Suppl 1), S84-S86.

Trolle E, Amiano P, Ege M, Bower E, Lioret S, Brants H et al. (2011b). Evaluation of $2 \times 24$-h dietary recalls combined with a foodrecording booklet, against a 7-day food-record method among schoolchildren. Eur J Clin Nutr 65 (Suppl 1), S77-S83.

Trolle E, Amiano P, Ege M, Bower E, Lioret S, Brants H et al. (2011c). Feasibility of $2 \times 24$-h dietary recalls combined with a foodrecording booklet, using EPIC-Soft, among schoolchildren. Eur J Clin Nutr 65 (Suppl 1), S65-S76.

Trubswasser U, Branca F (2009). Nutrition policy is taking shape in Europe. Public Health Nutr 12, 295-306. 